I N S T I T U T O

DE

M E D I C I N A

T R O P I C A L

DE

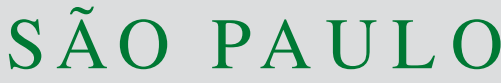

JOURNAL OF THE SÃO PAULO INSTITUTE OF TROPICAL MEDICINE

${ }^{1}$ Universidade de São Paulo, Faculdade de Medicina, Laboratório de Investigação Médica em Protozoologia, Bacteriologia e Resistência Antimicrobiana (LIM 49), São Paulo, São Paulo, Brazil

2Universidade de São Paulo, Laboratório de Virologia (LIM 52), São Paulo, São Paulo, Brazil

${ }^{3}$ Universidade de São Paulo, Faculdade de Medicina, Hospital das Clínicas, São Paulo, São Paulo, Brazil

${ }^{4}$ Universidade de São Paulo, Faculdade de Medicina, Departamento de Doenças Infecciosas e Parasitárias, São Paulo, São Paulo, Brazil

5Universidade de São Paulo, Instituto de Medicina Tropical de São Paulo, São Paulo, São Paulo, Brazil

Correspondence to: Silvia Figueiredo

Costa

Universidade de São Paulo, Instituto de Medicina Tropical de São Paulo,

Av. Dr. Enéas Carvalho de Aguiar, 470, Cerqueira César, CEP 05403-000,

São Paulo, SP, Brazil

Tel: +55 11943558668

E-mail: silviacosta@usp.br

Received: 18 June 2021

Accepted: 23 June 2021

\section{Are mobile phones part of the chain of transmission of SARS- CoV-2 in hospital settings?}

\author{
Evelyn Patricia Sánchez Espinoza', Marina Farrel Cortes', Saidy Vasconez \\ Noguera ${ }^{\circledR}$, Anderson Vicente de Paula ${ }^{2}$, Thais Guimarães ${ }^{3}$, Lucy Santos \\ Villas Boas ${ }^{2}$, Marcelo Park ${ }^{3}$, Cristina Carvalho da Silva ${ }^{3}$, Ingra Morales ${ }^{4}$, \\ Lauro Vieira Perdigão Neto', Tania Regina Tozetto-Mendoza ${ }^{2}$, Icaro

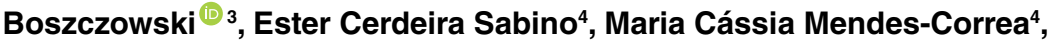 \\ Anna Sara Levin ${ }^{4}$, Silvia Figueiredo Costa ${ }^{\circledR 1,4,5}$
}

\section{ABSTRACT}

Mobile phones (MPs) have become an important work tool around the world including in hospitals. We evaluated whether SARS-CoV-2 can remain on the surface of MPs of first-line healthcare workers (HCW) and also the knowledge of HCWs about SARS-CoV-2 cross-transmission and conceptions on the virus survival on the MPs of HCWs. A crosssectional study was conducted in the COVID-19 Intensive Care Unit of a teaching hospital. An educational campaign was carried out on cross-transmission of SARS-CoV-2, and its permanence in fomites, in addition to the proper use and disinfection of MPs. Herewith an electronic questionnaire was applied including queried conceptions about hand hygiene and care with MP before and after the pandemic. The MPs were swabbed with a nylon FLOQ $\mathrm{Swab}^{\mathrm{TM}}$, in an attempt to increase the recovery of SARS-CoV-2. All MP swab samples were subjected to SARS-CoV-2 RT-PCR; RT-PCR positive samples were subjected to viral culture in Vero cells (ATCC ${ }^{\circledast}$ CCL-81 $1^{\mathrm{TM}}$ ). Fifty-one MPs were swabbed and a questionnaire on hand hygiene and the use and disinfection of MP was applied after an educational campaign. Most HCWs increased adherence to hand hygiene and MP disinfection during the pandemic. Fifty-one MP swabs were collected and two were positive by RT-PCR (4\%), with Cycle threshold $\left(C_{t}\right)$ values of 34-36, however, the cultures of these samples were negative. Although most HCWs believed in the importance of cross-transmission and increased adherence to hand hygiene and disinfection of MP during the pandemic, SARS-CoV-2 RNA was detected in MPs. Our results suggest the need for a universal policy in infection control guidelines on how to care for electronic devices in hospital settings.

KEYWORDS: SARS-CoV-2 hospital cross-contamination. Healthcare workers' mobile phones. SARS-CoV-2 on surfaces.

\section{BACKGROUND}

Mobile phones (MPs) have become an important work tool around the world including in hospitals. However, to date, there are no official policies from the Centers for Disease Control and Prevention (CDC) on their use or disinfection in healthcare facilities. The permanence of SARS-CoV-2 in inert hospital surfaces surrounding COVID-19 patients has been described ${ }^{1}$ raising the concern on cross transmission ${ }^{2}$. Even though SARS-CoV-2 has been found in MPs of symptomatic COVID-19 patients ${ }^{3}$, they have not been reported as source of transmission in the hospital. 


\section{MATERIALS AND METHODS}

This is a cross-sectional study performed in an adult Intensive Care Unit (ICU) of a university hospital in Sao Paulo, Brazil. The unit belongs to a 1,000-bed facility established as a COVID-19 reference center. The ICU has 11 separate patient-rooms (Figure 1). Healthcare workers (HCWs) wear laboratory coats, N95 face masks and surgical caps inside the unit and add a surgical gown, face shield and gloves when entering the patient room. An educational campaign on SARS-CoV-2 cross transmission, its permanence on fomites, and the proper use and disinfection of MPs was performed at the beginning of the pandemic. Informative posters were placed in the unit containing a $Q R$ code with access to a video of the campaign advising the use

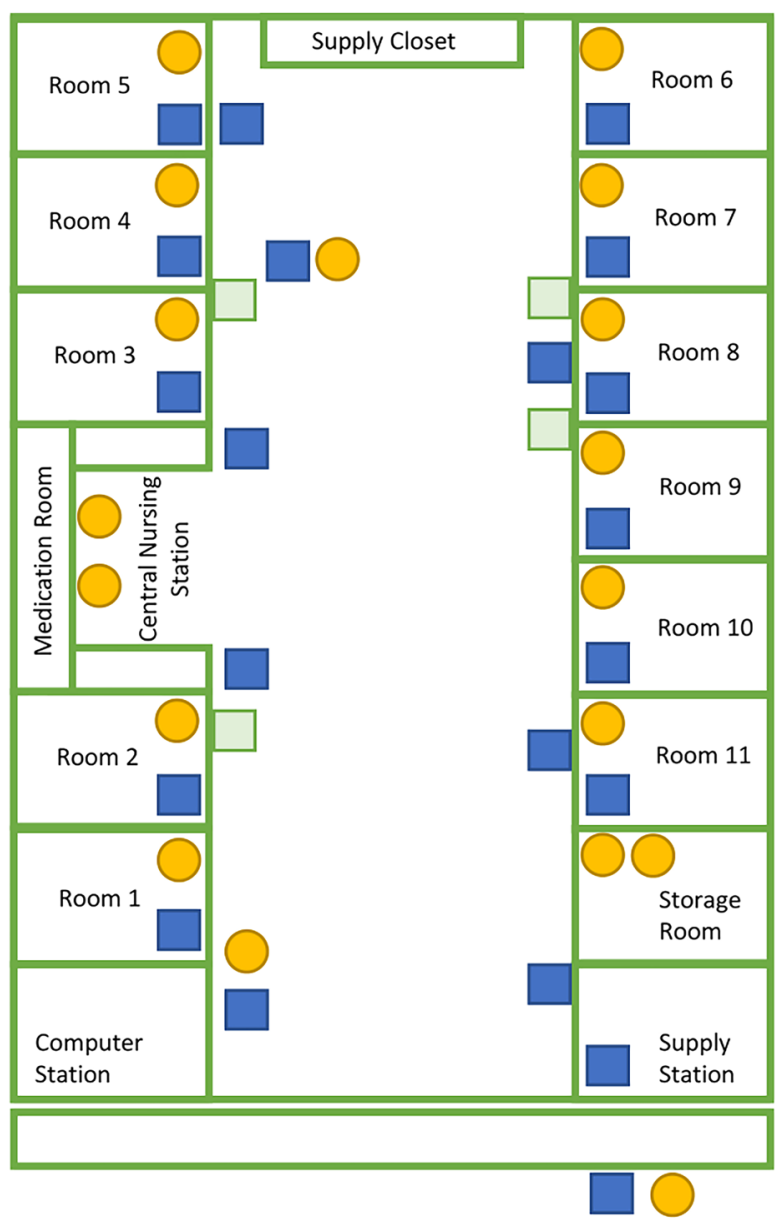

Alcohol Based Rub

Sink

Computer Station

Figure 1 - Layout of the COVID-19 Intensive Care Unit showing the distribution of hand rub dispensers and handwashing sinks in the unit. of swabs with $70 \%$ isopropyl alcohol for the disinfection of MPs, carefully avoiding the openings of the device and placing a screen protector to protect the oleophobic coating of the MP. We suggest doing this procedure before, during and after the shifts. It was also recommended to avoid the use of MPs during patient care and in the restroom.

Ten days after the campaign we collected samples of MPs from the HCW's And an electronic questionnaire was applied, including conceptions of hand hygiene and MP care before and after the pandemic. The MPs were swabbed with a nylon FLOQ Swab ${ }^{\mathrm{TM}}$ (Copan Italia SPA, Italy), in an attempt to increase the recovery of SARS-CoV-2. MPs were swabbed starting from the front screen and without removing their cases. After sampling, the swabs were placed in universal transport medium (UTM ${ }^{\mathrm{TM}}$ Copan Italia SPA, Italy) and stored at $-80^{\circ} \mathrm{C}$.

All of the MPs swab samples were submitted to SARS-CoV-2 RT-PCR. Positive reverse transcription polymerase chain reaction (RT-PCR) samples were submitted to viral culture. The RNA extraction was performed using the QIAmp viral RNA mini kit (QIAGEN, Hilden, Germany) according to the manufacturer's instructions. For the RT-PCR assay, the commercial RealStar $^{\circledR}$ SARS-CoV-2 Kit 1.0 (Altona-Diagnostics, Hamburg, Germany) was used, which qualitatively detects the presence of SARS-CoV-2 by amplifying the genes $\mathrm{S}$ and $\mathrm{E}$ of the virus. The amplification was carried out using the Roche Light Cycler ${ }^{\circledR} 96$ System (Roche Molecular Systems, Basel, Switzerland) and the sample was considered positive when at least one of the target genes was detected.

The culture was performed by inoculating an aliquot of the sample collected from the MPs into Vero cells $\left(\right.$ ATCC $^{\circledR}$ CCL-81 ${ }^{\mathrm{TM}}$ ), as previously described ${ }^{4,5}$, in Dulbecco minimal essential medium supplemented with fetal bovine serum (5\%), antibiotics and antimycotics (Cultilab, Campinas, SP, Brazil) at $37{ }^{\circ} \mathrm{C}$ in an atmosphere with $5 \% \mathrm{CO} 2$. Every day Vero cells were examined for cytopathic effect (CE), and new RT-PCRs were performed from the culture supernatant on the third, seventh and fourteenth days of culture.

\section{Ethics approval and consent to participate}

This research was approved by the Institucional Ethics Committee and Plataforma Brasil, process $\mathrm{N}^{\circ}$ 4.315.435. All the participants signed an informed consent to participate and the personal information of the participants is confidential.

\section{RESULTS}

During the educational campaign, the HCWs were interested and concerned on how to properly disinfect MPs 
to avoid unintentionally taking the virus home. The video of the campaign had 98 visualizations.

Fifty-one of the fifty-three HCWs of the unit participated in the survey [attending physicians $(n=7)$, cleaning staff $(n=5)$, nurses $(n=7)$, nursing assistants $(n=17)$, physiotherapists $(n=5)$, resident doctors/fellows $(n=10)$ ] and responded the questionnaire. Nine $(17.6 \%)$ had covered their MPs with plastic kitchen wrap in an attempt to facilitate disinfection. Eleven (21.6\%) did not remember the educational campaign and three $(5.9 \%)$ answered that the campaign did not change their behaviour. Only four $(7.8 \%)$ did not believe that the virus could remain on MPs and one (2\%) did not believe that the virus could remain on the hands; $98 \%$ reported washing their hands more often since the beginning of the pandemic (Table 1). Twenty-two COVID-19 patients were hospitalized in the unit during the study period, 11 (55\%) had positive SARS-CoV-2 RT-PCR in nasopharynx and oropharynx secretions and 20 (91\%) had lung computed-tomography suggestive of COVID-19.

Fifty-one MP swabs were collected, two were positive by RT-PCR (3.9\%), with Cycle threshold $\left(\mathrm{C}_{\mathrm{t}}\right)$ values of 34 and 36 , and in both cases the E-gene was detected. The two RT-PCR-positive samples were isolated in viral cultures. The sample with $\mathrm{C}_{\mathrm{t}} 34$ showed $\mathrm{CE}$ on the third day, but the subsequent RT-PCR of this isolate was negative. The isolate with $\mathrm{C}_{\mathrm{t}} 36$ did not show $\mathrm{CE}$, and the subsequent RTPCR of this isolate was negative, as well. The supernatant from both cultures was monitored for 14 days without observing any other CE. The swabs that had a positive SARS-CoV-2 RT-PCR corresponded to HCWs with high exposure to patients with COVID-19 (Table 1).

\section{DISCUSSION}

In this study, although most HCWs believed on the importance of cross transmission of SARS-CoV-2 and they increased the adherence to hand hygiene and MP disinfection during the pandemic, we identified SARS-CoV-2 on two MPs. Our findings suggest the need for a universal policy in the infection control guidelines on how to care for electronic devices in the hospital. Little is known about the permanence of viruses on MPs or their potential for cross-contamination. A study of MPs from HCWs of a pediatric unit ${ }^{6}$ found RNA viruses in $38.5 \%$ of the cases (42/109); predominantly of norovirus $(n=39)$.

In addition, two samples taken from continuous positive airway pressure (CPAP) helmets that were worn by patients with confirmed COVID-19, presenting with 10 or more days of symptoms and who tested positive by RT-PCR despite the fact that the surfaces be cleaned twice a day ${ }^{1}$. Presymptomatic patients with COVID-19 can also contaminate their surroundings. A study of quarantined asymptomatic student bedrooms showed that $8 / 22(36 \%)$ of the surfaces, including bedding, were positive. The students developed COVID-19 later ${ }^{7}$. Another study has recently shown that under controlled conditions, SARS-CoV-2 may persist on glass surfaces for 28 days and this is exactly the type of material used on the MPs touchscreens ${ }^{8}$.

This study has limitations. It is unclear what is the best method to collect the SARS-CoV-2 from MPs. Furthermore, the $\mathrm{C}_{\mathrm{ts}}$ found are high, corresponding to low viral loads ${ }^{9}$, even though the late amplification may have been caused by freezing and thawing the samples ${ }^{10}$.

\section{CONCLUSIONS}

Although most HCWs believed in the importance of cross-transmission and increased adherence to hand hygiene and disinfection of MPs during the pandemic, SARS-CoV-2 RNA was detected in two MPs. Our results suggest the need for a universal policy in infection control guidelines on how to care for electronic devices in the hospital.

Table 1 - Detection of SARS-CoV-2 by real-time polymerase chain reaction (RT-PCR) on mobile phones (MPs), and healthcare workers' ideas on hand hygiene and the use of mobile phones during the pandemic.

\begin{tabular}{|c|c|c|c|c|c|c|c|}
\hline $\begin{array}{l}\text { RT-PCR result / Answer to the } \\
\text { questionnaire }\end{array}$ & $\begin{array}{l}\text { Attending } \\
\text { physician } \\
(n=7)\end{array}$ & $\begin{array}{c}\text { Cleaning } \\
\text { staff } \\
(n=5)\end{array}$ & $\begin{array}{l}\text { Nurse } \\
(n=7)\end{array}$ & $\begin{array}{l}\text { Nursing } \\
\text { assistant } \\
(n=17)\end{array}$ & $\begin{array}{l}\text { Physiotherapist } \\
\qquad(\mathrm{n}=5)\end{array}$ & $\begin{array}{c}\text { Resident/ } \\
\text { fellow } \\
(n=10)\end{array}$ & $\begin{array}{l}\text { Total } \\
(\mathrm{n}=51)\end{array}$ \\
\hline Positive RT-PCR on mobile phones & 0 & 0 & $1(14.3 \%)$ & $1(5.9 \%)$ & 0 & 0 & $2(3.9 \%)$ \\
\hline $\begin{array}{l}\text { Believes SARS-CoV-2 can stay on } \\
\text { hands }\end{array}$ & $7(100 \%)$ & $4(80 \%)$ & $7(100 \%)$ & $16(94.1 \%)$ & $5(100 \%)$ & $10(100 \%)$ & $49(96 \%)$ \\
\hline $\begin{array}{l}\text { Increased hand-hygiene after } \\
\text { COVID-19 }\end{array}$ & $6(85.7 \%)$ & $5(100 \%)$ & $7(100 \%)$ & $17(100 \%)$ & $5(100 \%)$ & $10(100 \%)$ & $50(98 \%)$ \\
\hline $\begin{array}{l}\text { Believes SARS-CoV-2 can remain } \\
\text { on MPs }\end{array}$ & $7(100 \%)$ & $4(80 \%)$ & $7(100 \%)$ & $14(82.3 \%)$ & $5(100 \%)$ & $10(100 \%)$ & $47(92.1 \%)$ \\
\hline $\begin{array}{l}\text { Increased cleaning of MP after } \\
\text { COVID-19 }\end{array}$ & $6(85.7 \%)$ & $5(100 \%)$ & $7(100 \%)$ & $16(94.1 \%)$ & $5(100 \%)$ & $9(90 \%)$ & $48(94.1 \%)$ \\
\hline
\end{tabular}




\section{ACKNOWLEDGMENTS}

We would like to thank all the health workers and scientists fighting anonymously every day during the pandemic.

\section{AUTHORS' CONTRIBUTIONS}

EPSE contributed in the conception, design, acquisition and interpretation of data, and also substantially revised the manuscript; MCF, SVN, AVP, TG and LSVB contributed in the conception, design, acquisition and interpretation of data; MP gave authorization, contributed in the conception, interpretation of data, and encouraged the HCWS to participate actively; CCDS contributed in the conception, design and acquisition of data, supported the project and encouraged everyone to participate; IM contributed in the molecular analysis, interpretation of data, and also carried out the molecular experiments; LVPN, TGTM, IB, ES and MCMC encouraged the performance of the inquiry, contributed in the conception, design and interpretation of data; ASSL contributed in the conception, analysis and interpretation of data, supervised the results of this work and substantially revised the manuscript; SFC supported and encouraged this study, contributed in the conception, analysis and interpretation of data, supervised the molecular experiments and substantially revised the manuscript. All authors have approved the submitted version of this manuscript.

\section{CONFLICT OF INTERESTS}

The authors declare that they have no competing interests. There are no organizations of persons with financial interest or non-financial interests in the subject of this research.

\section{FUNDING}

This work was this project was partially supported by a Medical Research Council-Sao Paulo Research Foundation (FAPESP) CADDE partnership award (MR/S0195/1 and
FAPESP 18/14389-0). Also it was supported by using materials from LIM-49 Bacteriology Laboratory from the Universidade de Sao Paulo.

\section{REFERENCES}

1. Colaneri M, Seminari E, Novati S, Asperges E, Biscarini S, Piralla A, et al. Severe acute respiratory syndrome coronavirus 2 RNA contamination of inanimate surfaces and virus viability in a health care emergency unit. Clin Microbiol Infect. 2020;26:1094.e1-5

2. Panigrahi SK, Pathak VK, Kumar MM, Raj U, Priya PK. Covid-19 and mobile phone hygiene in healthcare settings. BMJ Glob Health. 2020;5:e002505.

3. Lei H, Ye F, Liu X, Huang Z, Ling S, Jiang Z, et al. SARS-CoV-2 environmental contamination associated with persistently infected COVID-19 patients. Influenza Other Respir Viruses. 2020;14:688-99.

4. Park WB, Kwon NJ, Choi SJ, Kang CK, Choe PG, Kim JY, et al. Virus isolation from the first patient with SARS-CoV-2 in Korea. J Korean Med Sci. 2020;35:e84.

5. Zhu N, Zhang D, Wang W, Li X, Yang B, Song J, et al. A novel coronavirus from patients with pneumonia in China, 2019. N Engl J Med. 2020;382:727-33.

6. Pillet S, Berthelot P, Gagneux-Brunon A, Mory O, Gay C, Viallon A, et al. Contamination of healthcare workers' mobile phones by epidemic viruses. Clin Microbiol Infect. 2016;22:456.e1-6.

7. Jiang FC, Jiang XL, Wang ZG, Meng ZH, Shao SF, Anderson $\mathrm{BD}$, et al. Detection of severe acute respiratory syndrome Coronavirus 2 RNA on surfaces in quarantine rooms. Emerg Infect Dis. 2020;26:2162-4.

8. Riddell S, Goldie S, Hill A, Eagles D, Drew TW. The effect of temperature on persistence of SARS-CoV-2 on common surfaces. Virol J. 2020;17:145.

9. Bullard J, Dust K, Funk D, Strong JE, Alexander D, Garnett L, Boodman C, et al. Predicting infectious SARS-CoV-2 from diagnostic samples. Clin Infect Dis. 2020;71:2663-6.

10. World Health Organization. Laboratory testing for 2019 novel coronavirus (2019-nCoV) in suspected human cases. [cited 2021 Aug 23]. Available from: https://www.who.int/ publications/i/item/10665-331501 